\title{
Bir Ucu Ankastre L Kirişin Gerinim Ölçer ile Serbest Sönümlü Titreşim Analizi
}

\author{
${ }^{1}$ Recep Yılmaz, ${ }^{2 *}$ SafaEldek, ${ }^{3}$ Erdi Gülbahçe \\ ${ }^{1}$ Tübitak UME, Ulusal Metroloji Enstitüsü, Gebze-Kocaeli, Türkiye \\ ${ }^{* 2}$ Mesa Makina Döküm Gıda San. ve Tic. A.Ş., Konya, Türkiye \\ ${ }^{3}$ Mekatronik Mühendisliği Bölümü, KTO Karatay Üniversitesi, Konya, Türkiye
}

\section{Özet}

$\mathrm{Bu}$ çalışmada bir ucu ankastre şekilde sabitlenmiş $\mathrm{L}$ tipi bir kirişin serbest sönümlü titreşim analizi gerçekleştirilmiştir. Sunulan çalışmada iki adet gerinim ölçer ile yarım köprü bağlantısı kullanılmış ve serbest sönümlü titreşim hareketi boyunca gerinim ölçerlerin yapıştırıldığı alandaki gerinim değerleri veri toplama cihazı ile ölçülmüştür. Ölçüm verileri Matlab yazılımı ile logaritmik azalma metodu kullanılarak işlenmiş ve kirişe ait sönüm periyodu $\left(T_{d}\right)$, sönüm oranı $(\xi)$ ve doğal frekans $\left(\omega_{n}\right)$ gibi titreşim parametreleri deneysel olarak elde edilmiştir.

Anahtar Kelimeler: Gerinim ölçer, Titreşim, Sönüm, Doğal frekans

\begin{abstract}
In this study, free damping vibration analysis of an L type beam with one end fixed is carried out. In the presented study, two strain gauges and half bridge connections were used and the strain values in the area where the strain gauges were adhered during the free-damped vibration motion were measured with a data acquisition device. The measurement data were processed by logarithmic decrement method with Matlab software and vibration parameters such as damping period (Td), damping ratio $(\xi)$ and natural frequency $\left(\omega_{\mathrm{n}}\right)$ of the beam were obtained experimentally.
\end{abstract}

Keywords: Strain gauge, Vibration, Damping, Natural Frequency

*Sorumlu Yazar: Safa Eldek Adres: Organize Sanayi Bölgesi İhsan Dede Caddesi 20 Nolu Sokak No:5,Konya, Türkiye. E-mail adres: safa.eldek@ mesamakina.com.tr, Telefon: +903322391872 


\section{Giriş}

Titreşim genel anlamda bir denge noktası etrafındaki mekanik salınım hareketi olarak ifade edilmektedir [1]. Titreşimler dinamik olarak çalışan sistemlerde istenmeyen bir durumdur. Makinelerde bağlantı parçalarına, ana yapılara ve eyleyici sistemlere büyük hasarlar verebilmektedir. Ayrıca mekanik titreşimler ses ve gürültülere sebep olarak insan sağlı̆̆ını ve konforunu etkilemektedirler. Bu yüzden titreşim ölçümleri ve analizleri mühendislik için önemli bir çalışma konusu olmuştur [2]. Titreşim biliminin temelini kütle yay damper sistemi oluşturmaktadır [1,3]. Bütün titreşim analizleri bu temel bilgiye dayandırılarak anlamlandırılır. Tek serbestlik dereceli bir sistem olan kütle-yay-damper sistemin de iki önemli parametresi doğal frekansı $\left(\omega_{n}\right)$ ve sönüm oranıdır $(\xi)$. Yapıların bu parametrelerinin belirlenmesinde birçok yöntem sunulmuştur [4]. Bunların başında modal analiz yöntemi gelmektedir. Fakat daha basit yapılarda yüksek maliyetli bu yöntemden başka titreşim analiz yöntemleri de mevcuttur. Sunulan bu çalışmada bir ucundan ankastre şekilde sabitlenen L tipi bir kirişin diğer ucundan uygulanan kuvvet kaldırıldıktan sonraki serbest sönümlü titreşim davranışı incelenmiştir. Sistemde yarım köprü olarak bağlanan iki adet gerinim ölçer kullanılmış ve eşit büyüklükte fakat zıt işaretli eğilmeye bağlı gerinimler bir veri toplama cihazı ile bilgisayara aktarılmıştır. Matlab yazılımı ile ölçüm sinyali işlenerek grafikler doğrultusunda malzemeye ait titreşim parametreleri belirlenmiştir.

\section{L Tipi Kiriş Tasarımı}

Tasarlanan L tipi kiriş ve sistemin genel görüntüsü Şekil 1'de gösterilmiştir. L tipi kirişin ankastre bağlantı noktasına iki adet eş konumlu gerinim ölçer yerleştirilmiştir. Kiriş malzemesi olarak St-37 çeliği kullanılmıştır. St-37 çeliğinin fiziksel ve mekanik özellikleri Tablo 1'de verilmiştir.

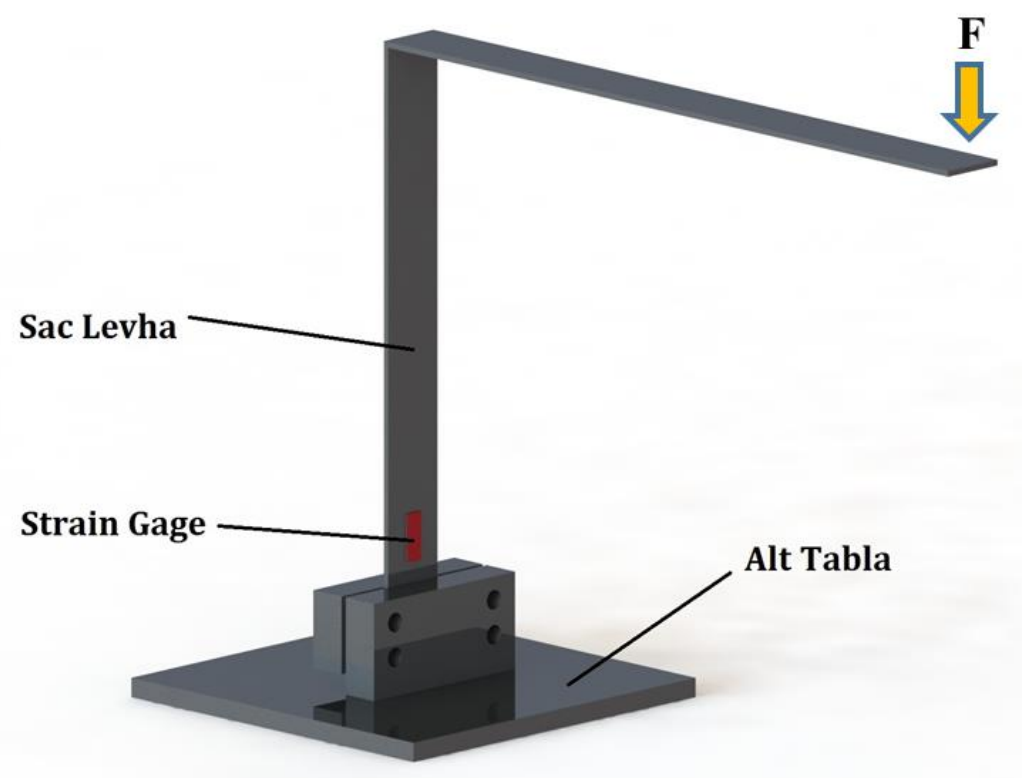

Şekil 1. L tipi kiriş ve sistemin genel görüntüsü 
Tablo 1. St-37 çeliği fiziksel ve mekanik özellikleri [5]

\begin{tabular}{|l|r|l|}
\hline Elastisite Modülü & $2.1 \mathrm{e} 5$ & $\mathrm{~N} / \mathrm{mm}^{2}$ \\
\hline Poisson Oranı & 0.28 & \\
\hline Gerilme Mukavemeti & 360 & $\mathrm{~N} / \mathrm{mm}^{2}$ \\
\hline Akma Mukavemeti & 235 & $\mathrm{~N} / \mathrm{mm}^{2}$ \\
\hline Termal Genişleme Katsayısı & $1.1 \mathrm{e}-5$ & $/ \mathrm{K}$ \\
\hline Kütle Yoğunluğu & 7800 & $\mathrm{~kg} / \mathrm{m}^{3}$ \\
\hline
\end{tabular}

L şeklindeki kiriş 400x35x2 mm ölçülerinde 2 parçadan oluşmaktadır ve köşe bağlantı yerinden kaynaklanmıştır. Alt tablanın profillerine açılan delikler ise cıvatalar yardımı ile kirişi ankastre olarak sabitlemek için kullanılmaktadır. Ölçüm düzeneğine ait boyutlar ve detaylı görünüm Şekil 2'de verilmiştir.
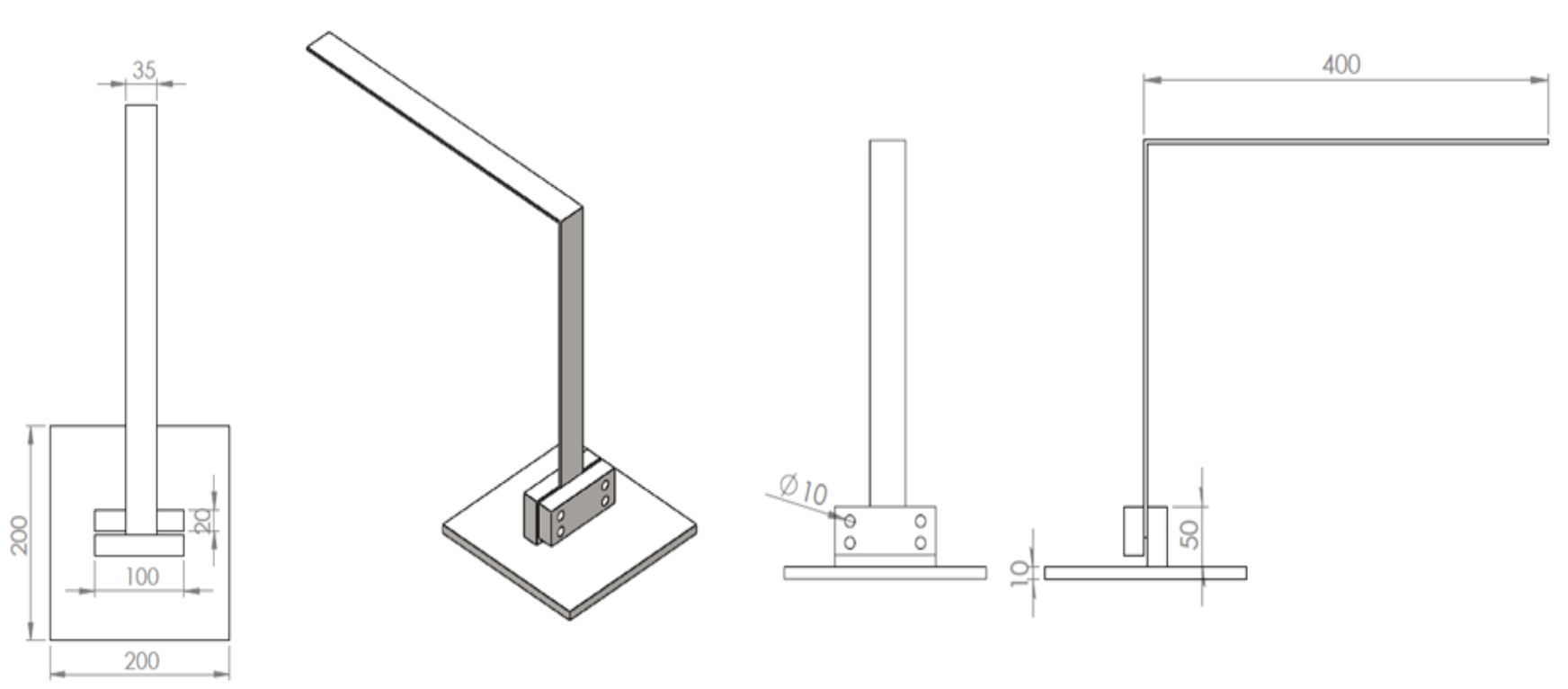

Şekil 2. Ölçüm düzeneğine ait ölçüler

\section{Gerinim Ölçer ve Uygulama Tekniği}

Genel olarak gerinim ölçerler, mekanik sistemlerde birim uzamayı, mekanik dönüşüm prensiplerini kullanarak meydana gelen gerilimleri ve eğer sistem salınım hareketleri yapıyorsa titreşimleri ölçmek için kullanılmaktadır. Gerinim ölçerler ince metal telden oluşmakta ve ölçüm yapılacak yerin üzerine sağlam bir şekilde yapıştırılmaktadır. Ölçüm yapılan noktada meydana gelen uzama veya kisalma, metal telde de uzama veya kisalma meydana getirmekte ve bu da telin elektriksel direncinde değişiklik meydana getirmektedir. Bu direnç değişimi Wheatstone köprüsü sayesinde voltaj değişikliğine çevrilmekte, elde edilen düşük voltaj uygun bir yükseltici ile yükseltilerek veri toplama sistemine gönderilmektedir [6]. 
Çalışmamızda iki adet Micro Measurement marka 120 S'luk gerinim ölçer kullanılmıştır. Aynı büyüklükteki gerinim ölçerler, L tipi kiriş üzerine Şekil 3'de gösterildiği gibi A ve B olarak birbirine göre simetrik konumlandırılarak yapıştırılmışııı.

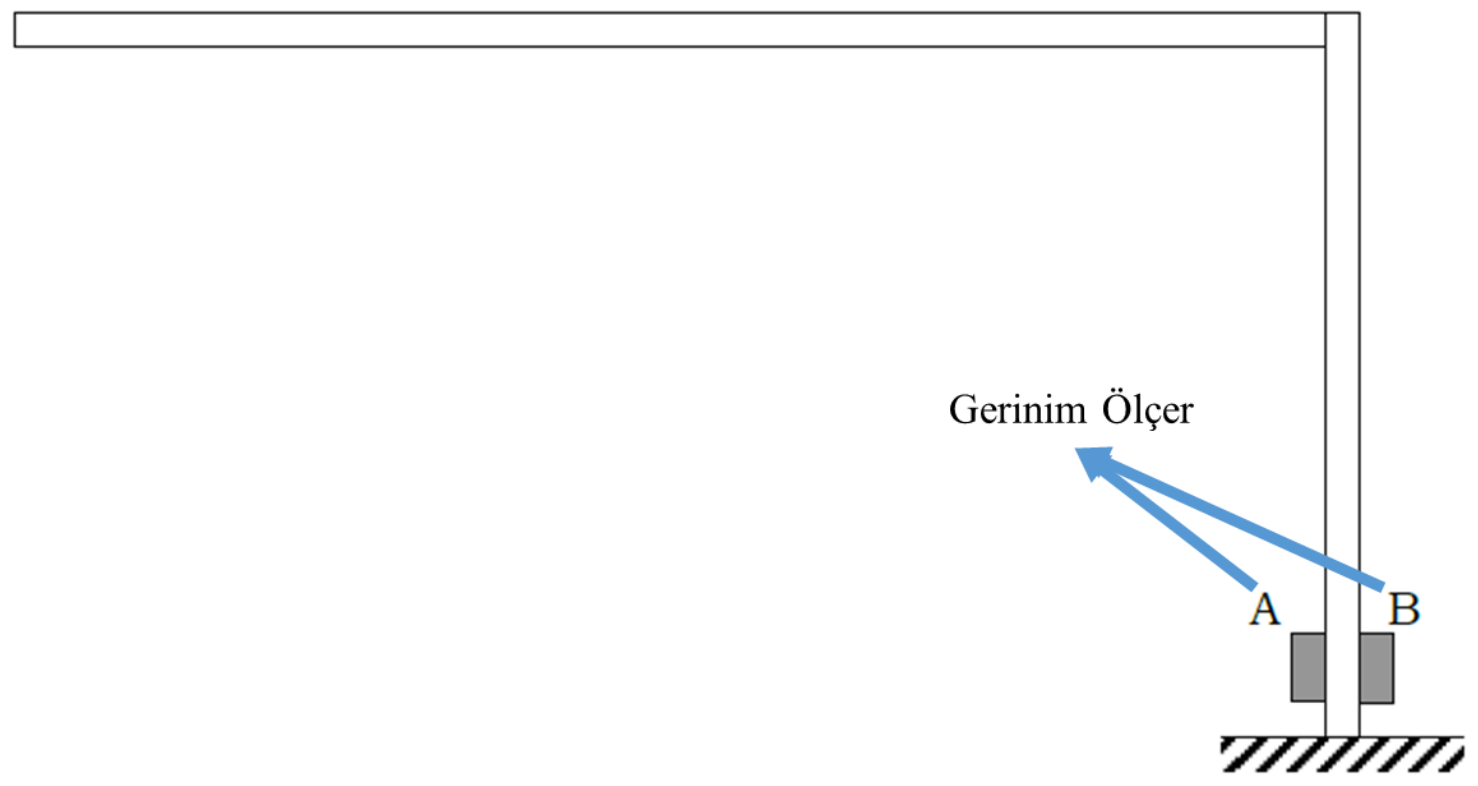

Şekil 3. Gerinim ölçerlerin uygulama şekli

Gerinim ölçerler çok ince ve hassas bir yapıya sahiptir ve bu yüzden yapıştırma işlemleri sırasında çok dikkatli olunmalıdır. Bu sensörlerin yapıştırılmaları sırasında oluşan sorunlar ölçüm yaparken büyük hatalara sebebiyet vermektedir. Bundan dolayı yapıştırma işleminden önce metal yüzey çok iyi bir şekilde temizlenmelidir. Temizlik işlemi bittikten sonra alkol ya da kolonya gibi sıvılar yardımı ile metal yüzey ince tozlardan arındırılmalıdır. Ardından gerinim ölçer, metale özel bir yapışıtırıcı yardımı ile sabitlenmelidir. Yapış̧ırma işlemi tamamlandıktan sonra kablo lehimleme işlemleri yapılarak gerinim ölçerler devreye bağlanmaktadır. Sistemde yarım köprü (half bridge) bağlantı şekli kullanılarak kablolama işlemi gerçekleştirilmiştir.

\section{Veri Toplama ve Matlab Yazılımı Yardımı ile Hesaplamalar}

Serbest sönümlü titreşim parametrelerinin elde edilebilmesi, tasarlanan sistemden doğru bir şekilde veri toplanabilmesi ile mümkün olmaktadır. Bu amaçla, deney sırasında gerinim ölçerlerden alınan veriler DEWESoft SIRIUS veri toplama cihazı ile toplanmıştır. DEWESoft SIRIUS veri toplama cihazı DEWESoft tarafindan üretilen, endüstriyel alanda kullanılan profesyonel bir cihazdır. Ayrıca bu cihaz yine aynı firmanın DEWESoftx yazılımı ile çalışmaktadır. $\mathrm{Bu}$ yazılım ile ölçüm verilerinin alınabilmesi için öncelikle yazılım parametrelerinin düzenlenmesi gerekmektedir. Sensör ayarlarının yapıldığı yazılım ara yüzü Şekil 4'de gösterilmiştir. Burada kullanılan gerinim ölçerin direnç değeri, gerinim ölçer faktörü, 
bağlantı tipi, ana yapı malzemesi yazılıma tanıtılmıştır. Dinamik sinyal ölçümü yapılacağından dolayı herhangi bir filtreleme yöntemi kullanılmamıştır.

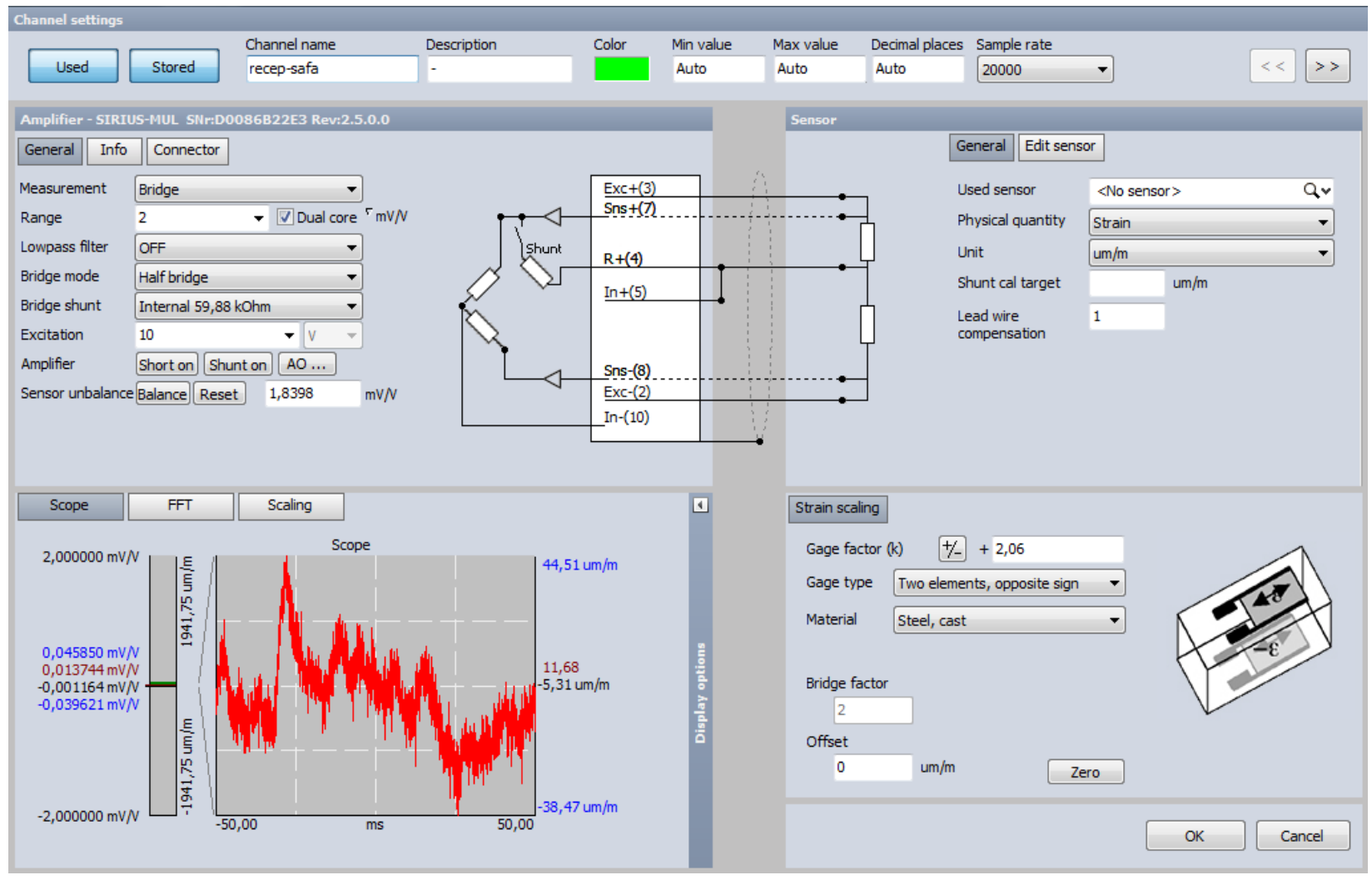

Şekil 4. Program parametreleri

Yazılım kurulumunun tamamlanmasının ardından Şekil 1'de gösterilen L tipi kirişin bir ucundan yapıyı plastik deformasyona uğratmayacak biçimde rastgele bir kuvvet (F) uygulanmıştır. Daha sonra bu kuvvet ortadan kaldırılmış ve yapı serbest sönüme bırakılmıştır. Ölçüm düzeneği ile alınan veriler DEWESoft veri toplama cihazından Matlab yazılımına eş zamanlı olarak PCI DAQ kartı yardımı ile aktarılmıştır. Gelen bu analog sinyaller Matlab/Simulink ile eş zamanlı olarak kaydedilmiştir. Burada iki önemli problemle karşılaşılmıştır. Bunlardan biri veri toplama cihazından gelen sinyalin 0 (sıfır) değeri etrafında salınım yapmamasıdır. Bu problemin çözümü için hazır olarak sunulan Kalman filtresi kullanılmıştır. Bir diğer problem ise kirişe uygulanan belirsiz yükün ardından ortalama ilk dört periyotta yüksek değerler elde edilmesidir. Titreşim genliğinin tepe sayıları belirlenirken bu problem hesaplamaları ciddi oranda etkilemektedir. $\mathrm{Bu}$ nedenle Simulink ara yüzünde ayarlanabilir bir anahtarlama kullanılmıştır. Ölçümün ilk iki saniyesi hesaba katılmamıştır. Matlab/Simulink yazılımda oluşturulan blok diyagram modeli Şekil 5'de verilmiştir. 


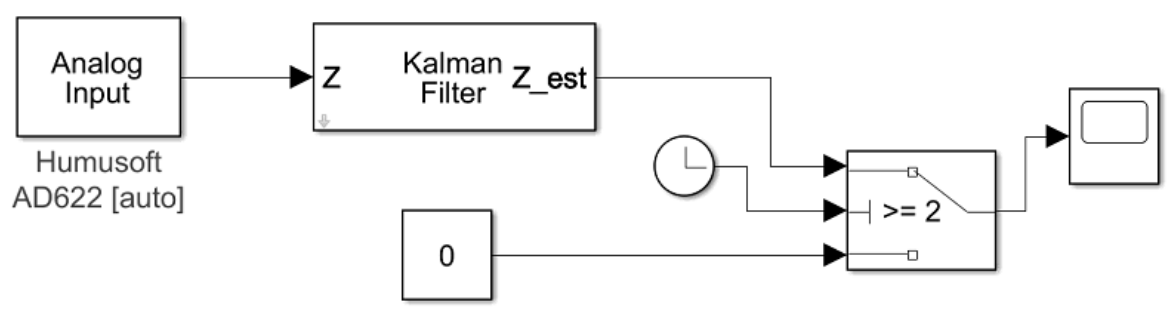

Şekil 5. Matlab/Simulink blok diyagram modeli

Oluşturulan model çalıştırıldıktan sonra veriler Matlab Workspace'e kaydedilmiştir. Hazırlanan bir m.file kodlaması ile genlik-zaman grafiği üzerindeki tepe noktaları önce program tarafından saydırılmış ve sıralanmıştır. Kodlama ile elde edilen grafik Şekil 6'da gösterilmiştir.

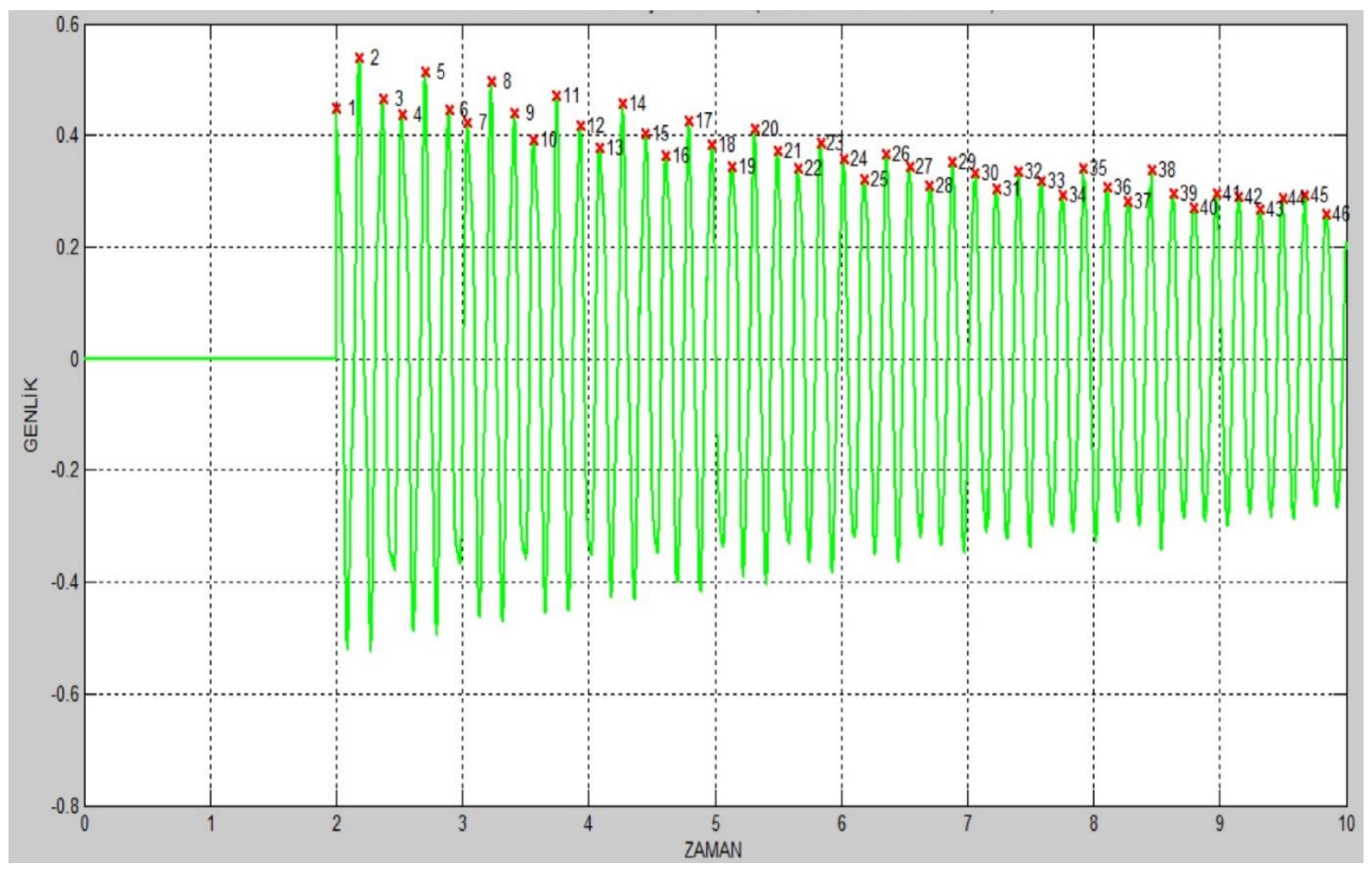

Şekil 6.Serbest sönümlü sistemin titreşim grafiği

Saydırma ve sıralama işleminin ardından, titreşim sinyalinden elde edilen veriler kullanılarak m.file dosyası içerisindeki logaritmik azalma metodu kodlamaları yardımıyla, yapının serbest sönümlü titreşim parametreleri belirlenmiş ve Matlab Workspace ekranına başarılı bir şekilde yazdırılmıştır. Bu çalışma kapsamında gerçekleştirilen serbest sönümlü titreşim analizine ait sonuçlar Şekil 7'de verilmiştir. 


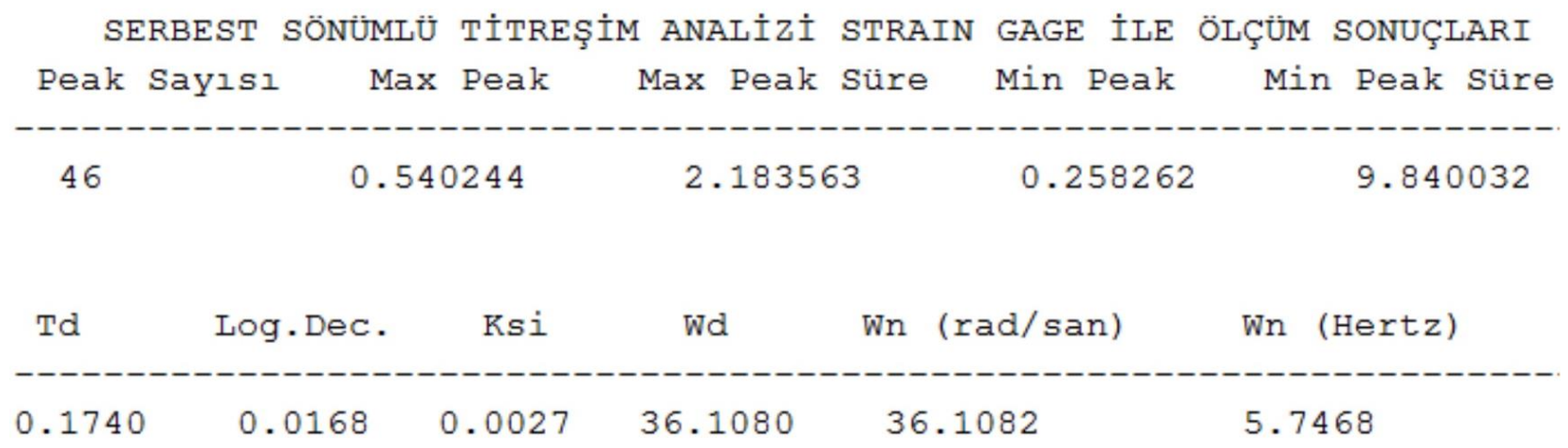

Şekil 7. Serbest sönüm titreşim analizi sonuçları

\section{Sonuç}

Bu çalışmada üretimi gerçekleştirilen L tipi kiriş biçimdeki bir test düzeneği ile deneysel serbest sönümlü titreşim testi gerçekleştirilmiştir. Test düzeneğinde birbirine simetrik olarak yapıştırılmış iki adet gerinim ölçer kullanılmıştır. Gerinim ölçerlerden elde edilen veriler bir veri toplama sistemi ile bilgisayara aktarılmış ve Matlab programı kullanılarak serbest sönümlü titreşim hareketine ait parametreler belirlenmiştir. Deneysel ölçümler yapılırken gerek ortamdaki elektriksel gürültüler gerekse malzeme özelliklerinden kaynaklanan küçük değer sapmalarına rastlanmıştır. Gerinim ölçerlerde kullanılan kablolar ortam gürültüsünden izole edilmiş olsa da ortamdaki diğer faktörler ve deney düzeneğinin sönüm oranının düşük olması sebebi ile her defasında istenilen değere yakın olmakla beraber farklı sonuçlar alınmıştır. Çevre şartlarından dolayı pürüzsüz bir sinyal elde edilemediğinden, program tarafından tepe noktaları hesaplanırken yanlış noktalar seçilebilmektedir. $\mathrm{Bu}$ da deneysel analizi az da olsa etkileyebilmektedir. Gerçekleştirilen ölçümlerde test düzeneğinin doğal frekansı $\left(\omega_{\mathrm{n}}\right)$ yaklaşık $5,74 \mathrm{~Hz}$ olarak bulunmuştur. $\mathrm{Bu}$ değer bozuk sinyallerde $6,20 \mathrm{~Hz}$ değerine kadar çıkabilmektedir. Sönüm oranı

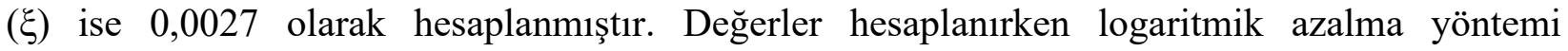
kullanılmıştır. Sonuç olarak başarılı bir ölçüm gerçekleştirilmiş ve sisteme ait serbest sönüm titreşim verilerine ulaşılmıştır.

\section{Kaynaklar}

[1] Kıral Z. Mekanik Titreşimler Ders Notları. http://kisi.deu.edu.tr/zeki.kiral/Mekanik _Titresimler_Ders_Notları_Zeki_Kiral.pdf

[2] Orhan S, Arslan H, Aktürk N. Titreşim Analiziyle Rulman Arızalarının Belirlenmesi. Gazi Üniversitesi Mühendislik-Mimarlık Fakültesi Dergisi, 2003, 18.2.

[3] İtik M. Mekanik titreşimler. http://mitik.ktu.edu.tr/assets/ch1_introduction.pdf 
[4] Beranek L.L. Noise and Vibration Control, Mc Graw Hill Books, New York, 1983.

[5] Metals Handbook, Howard E. Boyer and Timothy L. Gall, Eds., American Society for Metals, Materials Park, OH, 1985.

[6] Anderson D. J. Measurement of stress in mastication. I. Journal of Dental Research, 1956, 35.5: 664-670. 